\title{
A publicidade saudável na comunicação pública
}

\author{
Healthy advertising in public communication
}

La publicidad saludable en la comunicación pública

\section{Asdrúbal Borges Formiga Sobrinho1}

- Doutor em Psicologia pelo Instituto de Psicologia da Universidade de Brasília (UnB)

- Mestre em Comunicação pela Faculdade de Comunicação da UnB

- Professor da UnB

- Coordenador do projeto "A criatividade em processos e produtos da comunicação"

- E-mail: asdru_bal@uol.com.br

\footnotetext{
1 Este artigo apresenta resultados da pesquisa desenvolvida no projeto "A criatividade em processos e produtos da comunicação", coordenado pelo autor e integrado pelos bolsistas de iniciação científica da Universidade de Brasília (UnB) Saulo Mendes Batista, Erica Cael Alves e Alexandre Andrade da Silva Machado.
} 


\section{Resumo}

Este artigo discute as razões pelas quais o conceito de comunicação pública comumente não abrange a publicidade, nem sequer a publicidade de utilidade pública, devido, por exemplo, a estigmas da propaganda governamental ou da publicidade mercadológica. $\mathrm{O}$ texto demonstra a importância da publicidade de utilidade pública para a comunicação pública, teoricamente e por meio de imagens empregadas numa campanha que dialoga com estratégias persuasivas desenvolvidas pela publicidade mercadológica para promover a cidadania dos portadores de HIV.

PALAVRAS-CHAVE: COMUNICAÇÃO PÚBLICA - PUBLICIDADE - IMAGEM PÚBLICA • PUBLICIDADE DE UTILIDADE PÚBLICA • CIDADÃOS • SAÚDE

\section{Abstract}

This paper discusses the reasons why the concept of public communication often doesn't include the advertising, even the public one, due to, for example, stigmas from the government or market advertisement. The text shows the importance of the public advertisement for the public communication, in theory and by images adopted in a campaign which uses persuasive strategies developed by the market advertising to promote the citizenship of the HIV carriers.

KEYWORDS: PUBLIC COMMUNICATION • ADVERTISING - PUBLIC IMAGE - PUBLIC ADVERTISING • CITIZENS • HEALTH

\section{Resumen}

Este artículo debate las razones por las cuales el concepto de comunicación pública usualmente no incluye la publicidad, ni siquiera la publicidad de utilidad pública, debido, por ejemplo, a los estigmas de la propaganda gubernamental o de la publicidad mercadológica. El texto demuestra la importancia de la publicidad de utilidad pública para la comunicación pública teóricamente y por medio de imágenes utilizadas en una campaña que dialoga con estrategias persuasivas desarrolladas por la publicidad mercadológica para promover la ciudadanía de los portadores del VIH.

PALABRAS CLAVES: COMUNICACIÓN PÚBLICA - PUBLICIDAD - IMAGEN PÚBLICA • PUBLICIDAD DE UTILIDAD PÚBLICA • CIUDADANOS • SALUD 
$\mathbf{H}$ á inúmeras e, muitas vezes, controversas definições de comunicação pública, tendo autores sul-americanos do ramo identificado consensos sobre a finalidade de informar privilegiando o interesse público (Weber, 2011) ou para a cidadania (Duarte, 2011; Brandão, 2009); e sobre o fato de constituir um espaço de diálogo, participação (Bueno, 2009) e interação (Matos, 2011). Entretanto, também tem destaque entre eles o fato de o conceito ainda estar em construção, em razão de a pesquisa no ramo ainda ser recente.

Na literatura consultada, comumente se chama a atenção para a confusão entre comunicação pública e comunicação governamental, tendo a primeira sido apontada como solução para uma nomenclatura herdeira de um estigma da propaganda governamental ou política realizada durante a ditadura militar brasileira e os regimes totalitários europeus. Entretanto, a substituição gerou outros problemas: a associação de comunicação pública apenas à comunicação realizada pelo Governo; e o entendimento da comunicação pública como processo de uma determinada gestão do governo, efêmera, e não promovida pelo Estado, permanente.

\section{ABORDAGEM ESTIGMATIZADA NA COMUNICAÇÃO PÚBLICA}

O referido contexto aponta para o principal motivador deste artigo: a abordagem da publicidade em estudos de comunicação pública. Maria Helena Weber (2011, p. 110) é das poucas autoras a destacar o fato de ela, em substituição taxonômica à propaganda, estar "excluída conceitualmente da comunicação das democracias contemporâneas". Juan C. Jaramillo López (2011), por sua vez, a exclui da abrangência do conceito de comunicação pública e de sua dimensão midiática, por considerar que ela não pode ter fins estratégicos ou manipuladores. O autor ignora o potencial de contribuição da publicidade para processos de mobilização social, pois não reconhece a dimensão afetiva de organizações anunciantes sequer num nível simbólico; e considera a comunicação publicitária capaz apenas de convocar e persuadir para fins de consumo, mas não de conscientizar para adesão a alguma causa social.

A nomenclatura e a categorização referidas geram contradições, pois, embora possa ser legítima a busca de uma expressão mais voltada para promover ou reforçar a democracia, o novo nome não é suficiente para desestigmatizar qualquer gênero de comunicação e nem para eximi-lo de ações persuasivas ou manipuladoras comumente associadas à publicidade. Além do mais, como menosprezar a construção de uma imagem pública por uma campanha de utilidade pública, se as peças são veiculadas externamente, assinadas pelo governo e, inevitavelmente, dotadas de algum caráter institucional representativo da imagem e da identidade (Kunsch, 2003) de uma gestão, mesmo que este não deva ser primordial?

Imagem pública pode ser entendida como a combinação de dois modelos de representação. A primeira é a representação política, objetiva e tangível, pois vinculada à eleição ou ao lugar institucional conquistado, enquanto a segunda é a representação simbólica, subjetiva e tangível, porquanto vinculada aos modos de representar a representação (política) em lugares de visibilidade pública (Weber, 2011, p. 115). 
Como o âmbito simbólico consolida a substituição da relação direta entre os polos da comunicação, o conceito valoriza a participação do receptor no processo comunicativo, a partir da maneira como assimila conteúdos e atua como cocriador dos mesmos. Tal atuação depende do contexto cultural e psicossocial, determinantes também da permanência de uma imagem pública de acordo com a coerência entre os diferentes tipos de comunicação sobre o assunto correlato.

Inegavelmente, o objetivo institucional deve ter limites e a comunicação - principalmente no âmbito político, partidário ou governamental - precisa ser regulamentada para atender ao interesse público e garantir os direitos do cidadão. Porém, isso não significa que a publicidade deva ser tratada como gênero insidioso, pois a comunicação pública realizada pela administração pública, embora também sujeita a equívocos e críticas, já tende a ampliar e qualificar a publicidade (Weber, 2011). Isso porque ela representa mudanças no sentido de potencializar a voz de organizações públicas ou não governamentais, anteriormente privilégio de organizações privadas (Rolando, 2011); e de tal voz representar demandas dos cidadãos, principais contribuintes. Nesse sentido, o funcionamento de organizações públicas se baseia no de organizações privadas, procurando identificar, gerar e atender as demandas dos usuários, mas com a diferença de os lucros obtidos com as inovações no relacionamento, ainda que simbólicos, pertencerem a um amplo conjunto de clientes.

Tal contexto aponta para o fato de a associação da comunicação a um partido ou uma gestão do governo, além de ser determinante da credibilidade e, portanto, da eficácia do processo comunicativo, também poder contribuir para modificar escolhas posteriores e outras atuações dos cidadãos, caso as ações não correspondam às mensagens. Além do mais, a publicidade, tão acusada de legitimar o uso da estrutura de comunicação da máquina pública para atender interesses particulares, também se vale de recursos persuasivos para incentivar cidadãos a votar em plebiscitos, promover a paz no trânsito, evitar doenças, entre outras formas de participação política.

Portanto, há diversas formas de a comunicação governamental ser considerada pública. Delas destaco, no gênero de comunicação pública midiática escolhido e apresentado na segunda seção e no estudo de caso discutido na terceira, "proteger e promover a cidadania" (Brandão, 2009, p. 05) ao tratar de tema relacionado com a saúde e, diante dele, tentar gerar, consolidar ou modificar alguma atitude, possivelmente seguida por ação.

\section{ABORDAGEM SAUDÁVEL NA COMUNICAÇÃO PÚBLICA}

Como desempenhar a tarefa de falar em nome de cidadãos, sobre eles e para eles, sendo eles, simultaneamente, indivíduos e toda uma população? Além disso, como estabelecer uma comunicação capaz de atrair a atenção para temas de interesse público e influir nas formas de pensar e agir dos indivíduos, visando a benefícios comuns? 
Uma das categorias da comunicação pública mencionadas por Jorge Duarte $(2009$, p. 62) é a "de utilidade pública: sobre temas relacionados ao dia a dia das pessoas, geralmente serviços e orientações. Buscam informar, mobilizar, prevenir ou alertar a população ou setores específicos dela para temas de interesse". Há autores, como Wilson Bueno (2009), que também chamam a atenção para o fato de a comunicação pública não ser privilégio de organizações públicas ou governamentais, embora as práticas comunicacionais realizadas por tais organizações constituam os mais importantes espaços para sua efetivação, em razão das funções desempenhadas diante da sociedade. Da mesma forma, a informação de interesse público não é exclusividade do gênero jornalístico. É também característica da publicidade de utilidade pública, aquela diretamente envolvida em ações concretas de comunicação dos governos para melhorar a qualidade de vida da população. O fato é que a publicidade de utilidade pública visa mobilizar, levar o cidadão a adotar um determinado comportamento que lhe traga benefícios tangíveis para melhorar sua qualidade de vida (Costa, 2006, p. 22).

O conceito e o livro que o apresenta, Comunicação de interesse público, (Costa, 2006) - criticado por tratar de comunicação pública e ter sido escrito por publicitários - demonstram o intercâmbio entre gêneros de publicidade como possível consequência do que já vinha ocorrendo entre gêneros de comunicação, argumento este também destacado por Monteiro (2009). O fenômeno reflete mudanças políticas decorrentes do fato de a sociedade estar mais complexa e o Estado não mais poder identificar todas as demandas dos cidadãos; e da redução da máquina estatal como consequência de um cenário econômico que, paralelamente à implantação de um regime democrático, convida cada vez mais o cidadão a ampliar sua participação política. E um dos principais espaços de representatividade do cidadão é a comunicação pública realizada pelo governo.

O referido processo amplia os papéis de supostos receptores da comunicação, muitos dos quais puderam intensificar sua transformação em cidadãos quando conquistaram determinado potencial de consumo e o empregaram também na aquisição de informação ou conhecimento. Esta é uma das razões para o atual modelo brasileiro de comunicação pública ter começado a se consolidar durante a primeira gestão do Governo Lula, como consequência, continuidade e aprofundamento de políticas econômicas da gestão de Fernando Henrique Cardoso que contribuíram para incluir no mercado de consumo uma parcela significativa da população. No período de aceleração de mudanças na economia de países chamados de emergentes, Néstor García Canclini (1997) já argumentava que se tornar consumidor pode ser um dos caminhos para o exercício da cidadania e que as mudanças econômicas teriam reflexos importantes no contexto sociocultural, alguns deles apontados a seguir.

Paralelamente às conquistas econômicas, ao aumento do nível de informação e, portanto, da exigência de muitos indivíduos, a publicidade, tão experiente em tratar seus públicos como consumidores, também pode passar a tratá-los como cidadãos, sem que uma classificação se contraponha à outra. Isso se aplica à publicidade mercadológica, classificação paralela à comunicação mercadológica, focada na divulgação de produtos ou serviços de uma empresa e baseada em técnicas persuasivas passíveis de emprego em diálogo com recursos da comunicação institu- 
cional (Kunsch, 2003). Aplica-se também à publicidade de utilidade pública, embora em intensidades diferentes e com propósitos diversos. Como consequência, as novas exigências dos cidadãos consumidores e conscientes do fato de também serem contribuintes passaram a incluir mais criatividade e sentido estratégico da comunicação pública em forma de publicidade de utilidade pública, pois o interesse público não é algo tangível e nem estável, está sempre sujeito a negociações, cercado de tensões e, portanto, tendendo a ser ressignificado por indivíduos atuantes nos dois ou nos vários polos da comunicação.

Entretanto, é preciso que a publicidade de utilidade pública evite exageros ou equívocos ao cumprir a tarefa da comunicação pública de "centralizar o processo no cidadão" (Duarte, 2009, p. 59), pois deve partilhar com o indivíduo, e não transferir para ele, por exemplo, toda a responsabilidade sobre a saúde. E, como já existe uma tensão no fato de um tema como a aids, escolhido como exemplo, ser de âmbito político e também privado, por colocar em questionamento o bem-estar individual - tão recorrente na publicidade mercadológica - e o bem-estar social, além de informar e orientar ações, deve haver também espaço para o indivíduo identificar resultados de: suas medidas preventivas; seus cuidados posteriores, caso já tenha sido infectado; ou seu modo de lidar com portadores do HIV e situações que os envolvam.

\section{REMÉDIO CRIATIVO}

Para exemplificar que tipo de mudança pode ser expressa pela comunicação pública e ciente do fato de o gênero não se resumir à comunicação realizada pelo governo, mas também do fato de o Estado dever ser o principal representante dos direitos do cidadão, escolhi uma campanha de publicidade de utilidade pública referente ao Dia Mundial de Luta Contra a Aids. Ela foi veiculada no fim do ano 2009 e assinada pelo Ministério da Sáude, na gestão do presidente Lula. A figura 1 , a seguir, apresenta a peça veiculada na internet e cujo conteúdo integrou cartazes, anúncios, outdoors, entre outros tipos de peça.

Figura 1 - Dia Mundial de Luta Contra a Aids - 2009:

Peça veiculada na internet

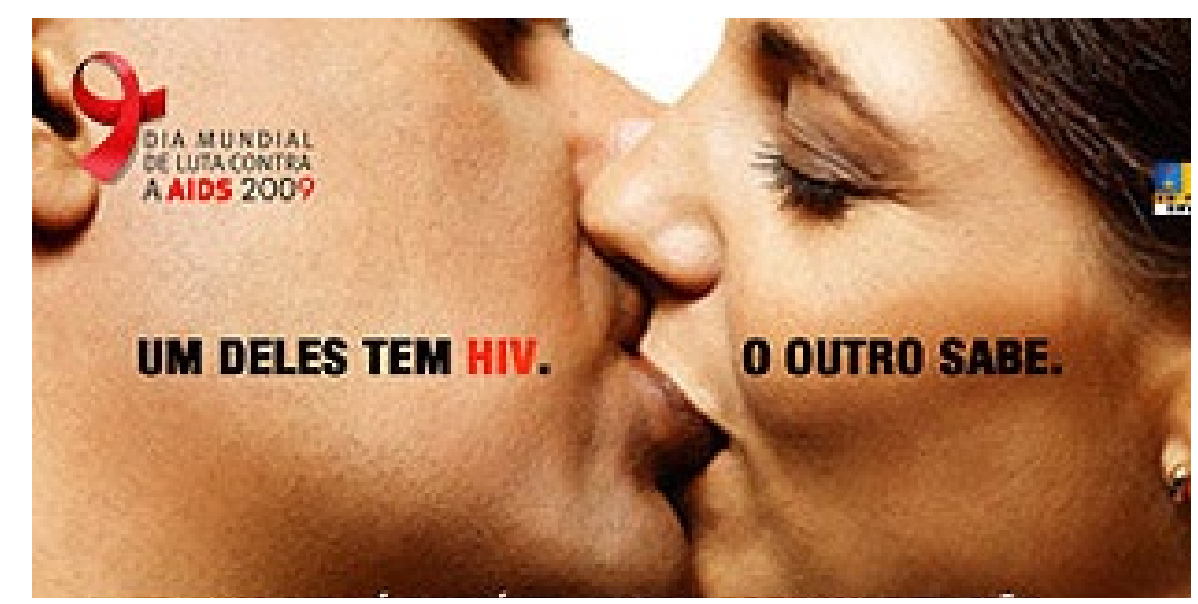


Inicialmente, chama a atenção o título composto, dividido em duas partes, cada uma sobreposta à imagem de um dos membros do casal - real, inclusive em relação ao título - que se beija, na foto: "Um deles tem HIV.; O outro sabe." Em seguida, o conjunto formado por título, imagem do casal se beijando e o texto com o tema da campanha: "Viver com aids é possível. Com o preconceito não".

O conteúdo dessa publicidade de utilidade pública tanto resume a polêmica na qual o tema está envolvido, quanto procura uma solução para a comunicação do mesmo e uma viabilidade para a eficácia das políticas públicas correlatas. Para isso, além de encontrar uma linguagem adequada e atraente e empregá-la nas peças publicitárias, é preciso mobilizar diferentes setores da sociedade.

Entretanto, há autores que não acreditam na publicidade para tais fins. Jaramillo López (2011), por exemplo, menciona que a mobilização contra a aids reúne pessoas com posicionamentos políticos diversos, entre as quais um acordo é praticamente impossível. Por outro lado, apresenta a necessidade de ajuste e negociação de um enfoque convergente, o que ocorreria por meio de processos comunicativos planejados por conhecedores de técnicas persuasivas preocupados com o interesse público e com a solução do problema de saúde também ocupante de territórios político, religioso e moral.

Diante da contradição, não faz sentido o autor ignorar a publicidade, se seu potencial argumentativo baseado na utilização de imagens lúdicas similares às apresentadas em gêneros de entretenimento pode garantir sucesso nesse diálogo. Ele sustenta os argumentos no fato de o êxito de políticas públicas do setor de saúde não depender de campanhas publicitárias, mas também de um conjunto de variáveis contextuais muitas vezes intangíveis. Assim, é importante insistir no fato de a publicidade de utilidade pública ser um dos instrumentos comunicativos capazes de construir, consolidar ou modificar a imagem pública não de uma gestão governamental, que certamente precisa emprestar sua credibilidade para o discurso publicitário, mas da própria aids. $\mathrm{E}$ isso em longo prazo, já que a publicidade sozinha, tanto no âmbito mercadológico quanto no público, pode ter efeitos efêmeros, mas principalmente no último caso, apenas ao ser veiculada, já contribui para colocar o assunto na pauta do debate público.

O referido autor não é o único a tentar excluir a publicidade da comunicação pública por limitá-la ao potencial pernicioso da publicidade mercadológica. Entretanto, o paralelo entre esta e a publicidade de utilidade pública aqui apresentado visa demonstrar como recursos já desenvolvidos no âmbito comercial podem ser empregados com outros fins.

Na publicidade mercadológica, doenças costumam estar ausentes, em razão do risco de repelirem a audiência interessada na representação de condições de felicidade, entre as quais se destaca a saúde, com base em imagens do corpo como território privado. Tal cenário protagonizado por pessoas jovens, saudáveis e sorridentes (Formiga Sobrinho, 2008), de certa forma, foi reproduzido pela publicidade de utilidade pública. Como o estilo de linguagem voltada para alertar ou assustar nunca foi o usual no ramo da saúde privada e já não é mais no ramo da saúde pública, inclusive porque não foi adequado sequer à geração que conviveu com a doença e a consequen- 
te morte rápida, foi necessário buscar um argumento mais sofisticado. O principal objetivo era dialogar com um público do qual foi afastada a imagem pública da aids como doença causadora de mortes, já que o assunto não está sempre presente na imprensa e as campanhas publicitárias são sazonais; e surgiram medicações para tratamentos capazes de garantir a longevidade dos infectados, tendo o Estado brasileiro realizado com sucesso sua distribuição.

O resultado da busca de elementos integradores da linguagem, portanto, foi favorecido por um progressivo processo de negociação com diferentes setores da sociedade e resultou na conquista de espaço num contexto cultural já favorável para mudanças, por exemplo, na linguagem de publicidade de utilidade pública de tal ramo de saúde (Paz, 2007). O produto das mudanças pode ser visto em imagens das últimas campanhas, majoritariamente focadas na prevenção e veiculadas às vésperas do Carnaval, mas cada vez mais contempladoras de práticas e diversidades sexuais. As recentes inclusões contaram com a contribuição, dentre outras, da referida campanha focada no combate ao preconceito, num primeiro nível de leitura, mas mantenedora do alerta para a prevenção, num nível implícito, pois, se é preciso compreender o fato de a aids não ter cara, também é preciso estar atento às formas de prevenção e buscar relações sexuais seguras, independentemente do parceiro.

Em outras palavras, personagens e cenários canônicos se repetiram, mas com um propósito cujo foco não está no consumo de produtos, e sim no instinto de preservação e na manutenção de um estilo de vida saudável ou de condições de felicidade. Com a saúde ameaçada, esses valores, antes mais presentes em conteúdos de publicidade mercadológica, podem ser negados ao indivíduo ou pode ser comprometido seu acesso a satisfações afetivas ou sexuais e mesmo ao trabalho. Isto é exemplificado de forma inclusiva em relação ao portador do HIV, numa peça radiofônica integrante da referida campanha de combate ao preconceito e viabilizador do consumo de produtos ou estilos de vida diversos.

Do ponto de vista político, existe, além da preocupação com os correlacionados bem-estares físico e psíquico individuais, fundamentais também para o bom funcionamento da sociedade, outra preocupação de cunho econômico, pois o Estado leva em consideração o custo do tratamento da aids e de doenças correlatas, assim como o custo das possíveis mortes consequentes. Portanto, investir em publicidade de utilidade pública, comunicação pública e políticas públicas preventivas custa menos do que a manutenção ou a perda de inúmeros infectados e pode contribuir significativamente para a imagem pública de uma gestão do governo, mas deve ter como principal propósito poupar muitas vidas e aprimorar tantas outras.

De qualquer forma, a publicidade de utilidade pública parece encontrar seu espaço saudável na comunicação pública para a construção progressiva de uma imagem pública da aids. O fato é que, embora precise do apoio de outras políticas públicas e de apresentar um discurso coerente com os proferidos em outras instâncias, não apenas de comunicação, ela procura proteger no sentido de tentar evitar que mais indivíduos sejam infectados; e promover a cidadania no sentido de contribuir para a socialização dos infectados. 


\section{CONSIDERAÇÕES FINAIS}

Estariam os criativos responsáveis pela concepção da campanha empregando uma estratégia persuasiva recorrente na publicidade mercadológica para garantir a eficácia da publicidade de utilidade pública? Ou estaria o anunciante, órgão da gestão de um Estado incapaz de realizar políticas públicas eficazes, procurando dividir sua função com a população, passível de colher desse processo alguma satisfação de âmbito afetivo ou moral?

A resposta é afirmativa para ambas as questões, desde que o resultado de campanhas públicas seja positivo e todos os setores envolvidos, mas principalmente os cidadãos, conquistem algum benefício. Diante disso, já não é mais possível conceber a publicidade apenas como mantenedora de um status quo, mas também como estabelecedora de elos entre Estado e cidadãos e, portanto, potencializadora de mudanças.

Os profissionais diretamente envolvidos com a criação da referida publicidade de utilidade pública certamente enfrentaram desafios relacionados com a busca de meios e estratégias de comunicação, assim como da linguagem ideal para dialogar com a maior parcela da população de um território tão extenso e caracterizado por uma grande diversidade cultural. E, quando se trata de um assunto como a aids, que, além de questões de saúde, envolve outras políticas e inclusive morais, o desafio se amplia. Diante dele

é legítimo perguntar se a administração pública tem o direito de lidar com a nossa felicidade pessoal. A resposta, naturalmente, é afirmativa, porque a felicidade pode ser entendida como um sentimento coletivo. Emoções e comportamentos agregam e desagregam em um território marcado por temores e por esperanças (Rolando, 2011, p. 36).

Também é legítimo considerar o desafio um importante motivador e incluir na comunicação pública realizada pela administração pública outros gêneros de comunicação capazes não apenas de prometer esperança, mas também de contribuir para a concretização de políticas cujos resultados contribuam para a sociedade ter esperança de fato, a partir também da inclusão cada vez mais ampla dos cidadãos no processo comunicativo.

\section{REFERÊNCIAS}

BRANDÃO, Elizabeth Pazito. Conceito de comunicação pública. In: DUARTE, Jorge (Org.). Comunicação pública: Estado, mercado, sociedade e interesse público. 2. ed. São Paulo: Atlas, 2009. p. 01- 33.

BRASIL. Dia Mundial 2009 - Viver com aids é possível. Com o preconceito não. Disponível em http://www.AIDS.gov.br/ campanha/dia-mundial-de-luta-contra-AIDS-2009. Acesso em 19/02/2012. 
BUENO, Wilson da Costa. Comunicação, iniciativa privada e interesse público. In: DUARTE, Jorge (Org.). Comunicação pública: Estado, mercado, sociedade e interesse público. 2. ed. São Paulo: Atlas, 2009. p. 134-153.

COSTA, João Roberto Vieira da. Comunicação de interesse público. In: COSTA, João Roberto Vieira da (Org.). Comunicação de interesse público: ideias que movem pessoas e fazem um mundo melhor. São Paulo: Jaboticaba, 2006. p. $19-27$.

DUARTE, Jorge. Instrumentos de comunicação pública. In: DUARTE, Jorge (Org.). Comunicação pública: Estado, mercado, sociedade e interesse público. 2. ed. São Paulo: Atlas, 2009. p. 59-71.

Sobre a emergência do(s) conceito(s) de comunicação pública. In: KUNSCH, Margarida M. Krohling (Org.). Comunicação pública, sociedade e cidadania. São Caetano do Sul (SP): Difusão, 2011. p. 121-134.

FORMIGA SOBRINHO, Asdrúbal Borges. Juventude consumida: significações de comerciais sobre jovens e para jovens. Brasília, 2008. Tese (Doutorado em Psicologia) - Instituto de Psicologia, Universidade de Brasília.

GARCÍA CANCLINI, Néstor. Consumidores e cidadãos 3. ed. Rio de Janeiro: Editora UFRJ, 1997.

JARAMILLO LÓPEZ, Juan Camilo. Advocacy: uma estratégia de comunicação pública. In: KUNSCH, Margarida M. Krohling (Org.). Comunicação pública, sociedade e cidadania. São Caetano do Sul (SP): Difusão, 2011. p. 61-80.

KUNSCH, Margarida M. Krohling. Planejamento de relações públicas na comunicação integrada. 4. ed. - rev., atual. e ampl. São Paulo: Summus, 2003.

MATOS, Heloiza. Comunicação pública: aportes teóricos e abrangência. In: KUNSCH, Margarida M. Krohling (Org.). Comunicação pública, sociedade e cidadania. São Caetano do Sul (SP): Difusão, 2011. p. 39-59.

MONTEIRO, Graça França. A singularidade da comunicação pública. In: DUARTE, Jorge (Org.). Comunicação pública: Estado, mercado, sociedade e interesse público. 2. ed. São Paulo: Atlas, 2009. p. 34-46.

PAZ, Josi. Aids anunciada: a publicidade e o sexo seguro. Brasília: UnB, 2007.

ROLANDO, Stefano. Comunicação pública: aportes teóricos e abrangência. In: KUNSCH, Margarida M. Krohling (Org.). Comunicação pública, sociedade e cidadania. São Caetano do Sul (SP): Difusão, 2011. p. 23-37.

WEBER, Maria Helena. Estratégias de comunicação de Estado e a disputa por visibilidade e opinião. In: KUNSCH, Margarida M. Krohling (Org.). Comunicação pública, sociedade e cidadania. São Caetano do Sul (SP): Difusão, 2011. p. 101-119. 